\title{
Deactivation of the Ruthenium Excited State by Enhanced Homogeneous Charge Transport: Implications for Electrochemiluminescent Thin Film Sensors
}

\author{
Emmet J. O’Reilly ${ }^{\mathrm{a}^{*}}$, Tia E. Keyes ${ }^{\mathrm{b}}$, Robert J. Forster ${ }^{\mathrm{b}}$, Lynn Dennany ${ }^{\mathrm{c}^{*}}$ \\ ${ }^{a}$ Bernal Institute, Department of Chemical Sciences, University of Limerick, Castletroy, Limerick, Ireland \\ ${ }^{b}$ National Centre for Sensor Research, School of Chemical Sciences, Dublin City University, Dublin 9, \\ Ireland
}

${ }^{c}$ WestCHEM, Department of Pure and Applied Chemistry, Technology and Innovation Centre, University of Strathclyde, Glasgow, G1 1RD, UK

\begin{abstract}
The Electrochemiluminescent $(E C L)$ performance of three ruthenium based metallopolymer platforms with different homogeneous charge transfer diffusion coefficients $\left(D_{C T}\right)$ is reported. Significantly, simultaneous detection of light and current in tandem with steady state photoluminescence studies demonstrate that increasing the rate of $\mathrm{Ru}^{3+}$ production via enhanced charge transport results in a decrease in ECL intensity of up to $82 \%$ when the concentration of the co-reactant, sodium oxalate, is low, i.e., sub-mM. Spectroelectrochemical studies demonstrate that for maximum sensitivity to be obtained, the electroactive properties of the polymeric support matrix need to be considered in tandem with luminophore, analyte and co-reactant concentrations.
\end{abstract}

Keywords: Electrochemiluminescence, Chemiluminescence, Quenching, Electroactive polymers, ECL sensor design, $\left[\mathrm{Ru}(\mathrm{bpy})_{3}\right]^{2+}$.

\section{${ }^{*}$ To whom correspondence should be addressed:}

Emmet J. O’Reilly, Email: Emmet.OReilly@ul.ie, Tel: +353 (0) 61234663

Lynn Dennany, Email: Iynn.dennany@strath.ac.uk, Tel:+44 (0) 1415484322 


\section{Introduction}

Electrochemiluminescence (ECL) has emerged as a powerful technique for ultrasensitive detection of a broad range of analytes [1-11]. Advances in nanostructured materials such as quantum and carbon nano-dots have played a significant role in establishing ECL as a robust and efficient tool for the detection of both chemical and biological species. However, $\left[\mathrm{Ru}(\mathrm{bpy})_{3}\right]^{2+}$ or closely related analogues continue to dominate the field[12,13]. This is primarily due to the high sensitivity, relatively high $\mathrm{ECL}$ efficiency and wide dynamic range afforded by transition metal based luminophores[1, 4, 14, 15]. For bio-sensing and diagnostic applications current research strategies for ruthenium based platforms focus on optimising the ECL efficiency, i.e., photons emitted per electron passed [16, 17]. Important approaches include new co-reactants and altering the electrochemical characteristics of the material itself so as to increase the charge transfer rate to produce more luminophores per unit time. To this end, attempts have been made to improve efficiency by immobilising the ruthenium species within or by tethering to an electroactive polymeric backbone capable of mediating charge transfer between metal centres [18]. Although this approach has exhibited significantly enhanced rates of charge transport in the ground state giving more intense ECL $[16,19]$ a decrease in ECL efficiency and ECL signal is often observed where analyte/co-reactant concentrations are low[16].

In this contribution, we report on the impact of changing the rate of $\mathrm{Ru}^{3+}$ generation by changing the structure of the metallopolymer and its subsequent effect on ECL emission where the co-reactant concentration is low, i.e., sub millimolar. Steady state quenching studies provide a unique insight into the limitations of this approach with respect to enhancing ruthenium based ECL emission. The impact of these findings on the design of future ruthenium based nanostructured ECL platforms for ultrasensitive detection is highlighted.

\section{Materials and Methods}

The metallopolymers, $\left[\mathrm{Ru}(\mathrm{bpy})_{2}(\mathrm{PPyBBIM})_{10}\right]^{2+}$ and $\left[\mathrm{Ru}(\mathrm{bpy})_{2}(\mathrm{PVP})_{10}\right]^{2+}$, were prepared as described previously, where bpy is 2,2'-bipyridyl, PPyBBIM is poly[2-(2-pyridyl)-bibenzimidazole], and PVP is poly-4-vinylpyridine[20, 21]. Glassy carbon macro working electrodes $(3 \mathrm{~mm})$ were modified by applying $15 \mu \mathrm{L}$ of an ethanolic solution of the metallopolymer or a $\left[\mathrm{Ru}(\mathrm{bpy})_{3}\right]^{2+} / \mathrm{Nafion}$ composite to the electrode surface. The surface coverage was determined by graphical integration of background corrected cyclic voltammograms (scan rate, $v<5 \mathrm{mV} \mathrm{s}^{-1}$ ). In all cases the surface coverage ranged from $1.4 \times 10^{-8}$ to $2.1 \times 10^{-8} \mathrm{~mol} \mathrm{~cm}^{-2}$. Potentials were measured versus a standard $\mathrm{Ag} / \mathrm{AgCl}$ aqueous reference electrode $(3 \mathrm{M} \mathrm{KCl})$. Measurements involving simultaneous detection of light and current utilized a $\mathrm{CH}$ instrument model 760B connected to an Oriel 70680 photomultiplier tube (PMT). An Oriel model IS520 gated intensified CCD coupled to an Oriel model MS125 spectrograph, was used to acquire ECL spectra. ECL experiments were carried out using sodium oxalate as co-reactant (pH 6).

Absorbance and photoluminescence were recorded using a Shimadzu UV-240 spectrophotometer and a Perkin-Elmer LS-50 luminescence spectrometer. Spectroelectrochemical experiments were performed in a quartz thin-layer spectroelectrochemical cell $(2 \mathrm{~mm}$ path length) using a $\mathrm{CH}$ Instruments model 660 potentiostat. An ITO modified electrode was used as the working electrode with platinum $(\mathrm{Pt})$ and $\mathrm{Ag} / \mathrm{AgCl}$ electrodes acting as counter and reference electrodes. $\mathrm{Ru}^{3+}$ concentrations at potentials ranging from $0.1-1.0 \mathrm{~V} \mathrm{vs}$. $\mathrm{Ag} / \mathrm{AgCl}$ were determined from the Nernst 
equation [22]. All photoluminescence spectra were corrected for any differences in ruthenium concentration using the electrochemically measured surface coverage to ensure accurate comparisons of relative signal intensity.

\section{Results and Discussion}

A key issue for any bio-sensing or diagnostic platform is not the overall intensity of signal produced but rather the effective signal to noise ratio. Given the inherently low background noise levels associated with $\mathrm{ECL}$ detection, the enhancement of ECL intensity or brightness is a clear strategy for improving sensitivity and lowering detection limits. When the co-reactant is freely available, the ECL intensity at a modified electrode is likely to be limited by the rate of charge transfer characterised by the homogeneous charge transfer diffusion coefficient $\left(D_{C T}\right)[3,16,23]$. In the case of ruthenium based $\mathrm{ECL}$, oxidation of the metal moiety to the $3+$ oxidation state at circa $1.0 \mathrm{~V}$ followed by reaction with an $\mathrm{ECL}$ co-reactant is the precursor to light generation from the $\mathrm{Ru}^{2+*}$ excited state luminophore. As the ECL co-reactant is typically present in excess one would expect that increased concentrations of ruthenium metal in the 3+ oxidation state will lead to increased ECL emission. As the amount of ruthenium within a modified layer is fixed, the rate of $3+$ regeneration is important since an enhanced rate could lead to brighter ECL, heightened sensitivity and therefore lower limits of detection (LOD).

Incorporation of ruthenium into a conducting polymer matrix or covalent tethering to a conducting polymer backbone have previously demonstrated enhanced rates of charge transfer in metallopolymer systems. Table 1 documents the homogenous charge transfer diffusion coefficient $\left(D_{C T}\right)$ for $\left[\mathrm{Ru}(\mathrm{bpy})_{2}(\mathrm{PVP})_{10}\right]^{2+},\left[\mathrm{Ru}(\mathrm{bpy})_{2}(\mathrm{PPyBBIM})_{10}\right]^{2+}$ and the ruthenium/Nafion composite film. These values were determined from fast scan $\left(100-500 \mathrm{mV} \mathrm{s}^{-1}\right)$ where the response is electrochemically reversible and not influenced by the rate of heterogeneous electron transfer or ohmic drop in conjunction with the Randles-Sevcik equation;

$$
i_{p}=2.65 \times 10^{5} n^{3 / 2} A D_{C T} V^{1 / 2} C
$$

The $D_{C T}$ for the highly conducting $\left[\mathrm{Ru}(\mathrm{bpy})_{2}(\mathrm{PPyBBIM})_{10}\right]^{2+}$ is an order of magnitude larger than the PVP based $\left[\mathrm{Ru}(\mathrm{bpy})_{2}(\mathrm{PVP})_{10}\right]^{2+}$ metallopolymer and the $\left[\mathrm{Ru}(\mathrm{bpy})_{3}\right]^{2+} /$ Nafion composite. This is consistent with the conducting polymer backbone mediating electron transfer between the metal centres thereby augmenting the intrinsic electron self-exchange rate [21]. Previous studies using $\left[\mathrm{Ru}(\mathrm{bpy})_{2}(\mathrm{PPyBBIM})_{\mathrm{x}}\right]$ metallopolymers have shown that charge compensating ions do not represent the rate determining step for homogenous charge transport, and that electron transfer, mediated by the conjugated polymer backbone limits the overall rate of charge transport [17]. In such cases a reduction in ruthenium oxidation/reduction potentials has also been observed. Figure 1 (a) shows the average comparative oxidative $\mathrm{ECL}$ response for $\left[\mathrm{Ru}(\mathrm{bpy})_{2}(\mathrm{PPyBBIM})_{10}\right]^{2+},\left[\mathrm{Ru}(\mathrm{bpy})_{2}(\mathrm{PVP})_{10}\right]^{2+}$ and $\left[\mathrm{Ru}(\mathrm{bpy})_{3}\right]^{2+} /$ Nafion films where the $\mathrm{ECL}$ emission for each has been normalised to take account of minor differences in the ruthenium surface coverage. At a co-reactant/analyte concentration of 0.5 $\mathrm{mM}$, a decrease in ECL intensity of circa $32 \%$ is observed for the highly conducting $\left[\mathrm{Ru}(\mathrm{bpy})_{2}(\mathrm{PPyBBIM})_{10}\right]^{2+}$ metallopolymer when compared to the $\left[\mathrm{Ru}(\mathrm{bpy})_{2}(\mathrm{PVP})_{10}\right]^{2+}$ metallopolymer, despite the significantly enhanced $D_{C T}$ rates observed for the former. Further analysis shows that when the co-reactant concentration is reduced to $0.2 \mathrm{mM}$, the observed ECL signal intensity for the $\left[\mathrm{Ru}(\mathrm{bpy})_{2}(\mathrm{PPyBBIM})_{10}\right]^{2+}$ metallopolymer is circa $82 \%$ lower than the $\left[\mathrm{Ru}(\mathrm{bpy})_{2}(\mathrm{PVP})_{10}\right]^{2+}$ 
metallopolymer despite containing the equivalent amount of ruthenium. At co-reactant/analyte concentrations of $0.1 \mathrm{mM}$ no discernible $\mathrm{ECL}$ signal was observed for the $\left[\mathrm{Ru}(\mathrm{bpy})_{2}(\mathrm{PPyBBIM})_{10}\right]^{2+}$ metallopolymer (Figure 1 (a) inset). ECL studies utilising sub $\mathrm{mM}$ concentrations of TPA co-reactant also revealed significantly reduced $E C L$ emission for the $\left[\mathrm{Ru}(\mathrm{bpy})_{2}(\mathrm{PPyBBIM})_{10}\right]^{2+}$ metallopolymer system with no visible ECL signal being observed at $0.1 \mathrm{mM}$ TPA.

Table 1 displays the calculated ECL efficiency for each polymer matrix at a co-reactant (oxalate) concentration of $0.2 \mathrm{mM}$. The overall ECL efficiency $\left(\phi_{\mathrm{ECL}}\right)$ is defined as the number of photons emitted per faradaic electron passed during the chemiluminescent reaction[24]. It is the product of the efficiency of populating the excited state $\left(\phi_{\mathrm{Ex}}\right)$ and the quantum yield of emission from that excited state $\left(\phi_{\mathrm{P}}\right)$. Solution phase $\left[\mathrm{Ru}(\mathrm{bpy})_{3}\right]^{2+}$ was used as a relative standard for all experiments. The relative efficiency of each material was obtained using the equation;

$$
\phi_{\mathrm{ECL}}=\phi_{\mathrm{ECL}}^{0}\left(/ Q_{f}^{0} / Q_{f} /^{0}\right)
$$

where $\phi^{0}{ }_{\mathrm{ECL}}$ is the ECL efficiency of $\mathrm{Ru}(\mathrm{bpy})_{3}{ }^{2+}$ via annihilation, taken as $5.0 \%[25,26] I$ and $I^{0}$ are the integrated photomultiplier tube responses for the polymer and $\left[\mathrm{Ru}(\mathrm{bpy})_{3}\right]^{2+}$ respectively, and $Q_{f}$ and $Q_{f}^{0}$ are the faradaic charges passed for the sample and standard. It is important to note that as $\left[\mathrm{Ru}(\mathrm{bpy})_{3}\right]^{2+}$ itself cannot be immobilized directly as a thin film, the ECL efficiencies of the films are compared to $100 \mu \mathrm{M}\left[\mathrm{Ru}(\mathrm{bpy})_{3}\right]^{2+}$ in solution. At a co-reactant concentration of $0.2 \mathrm{mM}$ the highest $\mathrm{ECL}$ efficiency is obtained from the $\left[\mathrm{Ru}(\mathrm{bpy})_{2}(\mathrm{PVP})_{10}\right]^{2+}$ film closely followed by the Nafion- $\left[\mathrm{Ru}(\mathrm{bpy})_{3}\right]^{2+}$. Previous work has highlighted the capability of the negatively charged Nafion polymer to quench ruthenium based ECL emission[27]. Quenching however has only been reported for ultra-thin Electrochemiluminescence of $\mathrm{Ru}(\mathrm{bpy})_{3}{ }^{2+}$ loaded Nafion Langmuir-Blodgett films up to $0.5 \mu \mathrm{M}$ thick and is considered negligible in this case.

The ECL emission intensity for the conjugated $\left[\mathrm{Ru}(\mathrm{bpy})_{2}(\mathrm{PPyBBIM})_{10}\right]^{2+}$ metallopolymer was almost an order of magnitude lower than that obtained for the $\left[\mathrm{Ru}(\mathrm{bpy})_{2}(\mathrm{PVP})_{10}\right]^{2+}$ metallopolymer despite displaying faster rates of charge transfer. The dependence of the ECL intensities on the supporting polymer structure observed here have significant consequences for assays where the target itself is a co-reactant, e.g., guanine or certain amino acids, or where a secondary antibody is labelled with a coreactant.

It has previously been shown that $\mathrm{Ru}^{3+}$ acts as an efficient electron acceptor and quenches $\mathrm{Ru}^{2+*}$ emission particularly when confined within a film structure [21]. However, the impact of immobilising the luminophore within an electronically conducting matrix on this process has not been extensively investigated, e.g., the acceptor states of a conducting polymer could enhance quenching [17]. To investigate the importance of this effect for these metallopolymers, spectroelectrochemical investigations were performed. The spectroelectrochemical analysis focussed on the influence of $\mathrm{Ru}^{3+}$ concentrations on the photoluminescence intensities of the polymeric films. Figure 2 (a) illustrates the effect of electrochemically titrating in defined concentrations of $\mathrm{Ru}^{3+}$ into a $\left[\mathrm{Ru}(\mathrm{bpy})_{2}(\mathrm{PPyBBIM})_{10}\right]^{2+}$ metallopolymer film on the intensity of the observed optically driven ruthenium emission at $612 \mathrm{~nm}$. The increasing concentrations of $\mathrm{Ru}^{3+}$ were achieved using a graphical integration of the Nernst equation to determine the $\mathrm{Ru}^{3+}$ concentration at each potential. Utilising this, the $\mathrm{Ru}^{3+}$ concentration 
was varied by stepping the potential in $100 \mathrm{mV}$ increments until a steady state was reached and the emission monitored at this point. Potentials were stepped between 0.1 and $1.0 \mathrm{~V} \mathrm{vs} \mathrm{Ag} / \mathrm{AgCl}$.

It is important to note that because the composition of the film is being controlled electrochemically, some of the loss of luminescence intensity arises because the $\mathrm{Ru}^{2+}$ concentration decreases as the $\mathrm{Ru}^{3+}$ is created. Therefore, the emission intensities were corrected to reflect the actual $\mathrm{Ru}^{2+}$ concentrations. Varying the steady state potential from $0.1-1.0 \mathrm{~V}$ vs $\mathrm{Ag} / \mathrm{AgCl}$ results in an $84 \%$ reduction in emission intensity at the $\left[\mathrm{Ru}(\mathrm{bpy})_{2}(\mathrm{PPyBBIM})_{10}\right]^{2+}$ film. This is significantly higher than the circa $29 \%$ and $40 \%$ reduction observed for the $\left[\mathrm{Ru}(\mathrm{bpy})_{3}\right]^{2+} /$ Nafion and $\left[\mathrm{Ru}(\mathrm{bpy})_{2}(\mathrm{PVP})_{10}\right]^{2+}$ films respectively (Figure $2(\mathrm{~b})$ and (c)). This result suggests that the increased rate of homogenous charge transfer leads to increased quenching of the $\mathrm{Ru}^{2+*}$ excited state in the solid state. As both quencher and luminophore are immobilised on a polymeric backbone the Perrin model describes the static quenching process. The Perrin model assumes that there is instantaneous quenching of an excited donor by the quencher if it is located inside a sphere of volume $V_{q}$ around the fluorophore, and there is no quenching when the quencher is outside of this quenching sphere:

$$
\begin{aligned}
& \ln \left(I_{0} / I\right)=K_{p}[Q] \\
& K_{p}=V_{q} \mathrm{~N}_{\mathrm{A}}=4 / 3 \pi R_{s}{ }^{3} \mathrm{~N}_{\mathrm{A}}
\end{aligned}
$$

where $V_{q}$ is the quenching sphere, $\mathrm{N}_{\mathrm{A}}$ is Avogadro number, $I$ and $I_{0}$ are the fluorescence intensity in the presence and absence of the quencher and $R_{s}$ is the radius of the quenching sphere. Figure 2 (d) shows the static quenching response for composite films of $\left[\mathrm{Ru}(\mathrm{bpy})_{2}(\mathrm{PPyBBIM})_{10}\right]^{2+}$ (black squares), $\left[\mathrm{Ru}(\mathrm{bpy})_{2}(\mathrm{PVP})_{10}\right]^{2+}$ (red triangles) and $\left[\mathrm{Ru}(\mathrm{bpy})_{3}\right]^{2+} /$ Nafion (blue circles) based on the steady state optical emission intensity data in Figure 2 (a), (b) and (c) respectively. Table 1 documents the quenching sphere radii for each of the polymer systems as deduced from Equation 3. The quenching response shows that the radius of the quenching sphere for the $\left[R u(b p y)_{2}(\operatorname{PPyBBIM})_{10}\right]^{2+}$ metallopolymer is approximately $36 \%$ larger than that of the $\left[\mathrm{Ru}(\mathrm{bpy})_{3}\right]^{2+} /$ Nafion polymer most likely because of the higher rate of homogenous charge transfer.

When considered in tandem, ECL and steady state luminescence results suggest that given the close proximity of the ruthenium metal centres within the film, electrochemically generated $\mathrm{Ru}^{3+}$ has the potential to not only react with the co-reactant but to deactivate adjacent ruthenium excited states. Significantly, the findings suggest that the co-reactant availability limits the ECL intensity, e.g., when it is present at sub mM concentrations, enhanced charge transport and thus an increased concentration of $\mathrm{Ru}^{3+}$ may hinder rather than enhance $\mathrm{ECL}$ light production. With respect to $\mathrm{ECL}$ sensor design this is especially relevant where the co-reactant is the analyte and is present at low concentrations or the target analyte is labelled with co-reactant. The results suggest that to obtain maximum sensitivity, the analyte/co-reactant concentration needs to be considered when selecting $\mathrm{ECL}$ materials for their respective analysis. This is contrary to the "one size fits all" approach currently pursued with respect to ECL sensor design.

\section{Conclusions}

This work quantifies increased luminescent quenching as a function of enhanced homogenous charge transport in the solid state. Perrin model quenching studies demonstrate a larger quenching sphere for metallopolymer systems with enhanced rates of homogenous charge transport. The findings 
demonstrate that at high analyte/co-reactant concentrations enhanced charge transport has the potential to significantly increase ECL light production, however at lower concentration ranges materials with a slower rate of charge transport may be more favourable if optimal ECL light generation is to be obtained.

\section{Acknowledgements}

The authors acknowledge financial support from the Marie-Curie Reintegration Grant (PIRG-2010268236), Science Foundation Ireland (SFI), under CSET grant number 10/CE/B1821.

\section{References}

[1] Z. Liu, W. Qi, G. Xu, Recent advances in electrochemiluminescence, Chemical Society Reviews, 44 (2015) 3117-3142.

[2] Y. Xu, J. Liu, C. Gao, E. Wang, Applications of carbon quantum dots in electrochemiluminescence: A mini review, Electrochem Commun, 48 (2014) 151-154.

[3] P. Bertoncello, A. Stewart, L. Dennany, Analytical applications of nanomaterials in electrogenerated chemiluminescence, Analytical and bioanalytical chemistry, 406 (2014) 5573-5587.

[4] P. Bertoncello, R.J. Forster, Nanostructured materials for electrochemiluminescence (ECL)-based detection methods: Recent advances and future perspectives, Biosensors and Bioelectronics, 24 (2009) 3191-3200.

[5] S.K. Kirschbaum, A. Baeumner, A review of electrochemiluminescence (ECL) in and for microfluidic analytical devices, Analytical and bioanalytical chemistry, 407 (2015) 3911-3926.

[6] A.J. Stewart, E.J. O'Reilly, R.D. Moriarty, P. Bertoncello, T.E. Keyes, R.J. Forster, L. Dennany, A Cholesterol Biosensor Based on the NIR Electrogenerated-Chemiluminescence (ECL) of Water-Soluble CdSeTe/ZnS Quantum Dots, Electrochim Acta, 157 (2015) 8-14.

[7] A.J. Stewart, J. Hendry, L. Dennany, Whole Blood Electrochemiluminescent Detection of Dopamine, Anal Chem, 87 (2015) 11847-11853.

[8] R. Russell, A.J. Stewart, L. Dennany, Optimising electrogenerated chemiluminescence of quantum dots via co-reactant selection, Analytical and bioanalytical chemistry, 408 (2016) 7129-7136.

[9] I. Rubinstein, A.J. Bard, Polymer films on electrodes. 4. Nafion-coated electrodes and electrogenerated chemiluminescence of surface-attached tris(2,2'-bipyridine)ruthenium(2+), J Am Chem Soc, 102 (1980) 6641-6642.

[10] A. Juzgado, A. Solda, A. Ostric, A. Criado, G. Valenti, S. Rapino, G. Conti, G. Fracasso, F. Paolucci, $M$. Prato, Highly sensitive electrochemiluminescence detection of a prostate cancer biomarker, Journal of Materials Chemistry B, 5 (2017) 6681-6687.

[11] I. Rubinstein, A.J. Bard, Electrogenerated chemiluminescence. 37. Aqueous ecl systems based on tris(2,2'-bipyridine)ruthenium(2+) and oxalate or organic acids, J Am Chem Soc, 103 (1981) 512-516.

[12] E.J. O'Reilly, P.J. Conroy, S. Hearty, T.E. Keyes, R. O'Kennedy, R.J. Forster, L. Dennany, Electrochemiluminescence platform for the detection of C-reactive proteins: application of recombinant antibody technology to cardiac biomarker detection, RSC Advances, 5 (2015) 6787467877.

[13] J.S. Yuk, E. O'Reilly, R.J. Forster, B.D. MacCraith, C. McDonagh, Demonstration of surface plasmoncoupled emission using solid-state electrochemiluminescence, Chemical Physics Letters, 513 (2011)

112-117.

[14] L. Hu, G. Xu, Applications and trends in electrochemiluminescence, Chemical Society Reviews, 39 (2010) 3275-3304.

[15] D. Ege, W.G. Becker, A.J. Bard, Electrogenerated chemiluminescent determination of tris(2,2'bipyridine)ruthenium ion (Ru(bpy)32+) at low levels, Anal Chem, 56 (1984) 2413-2417. 
[16] E.J. O'Reilly, T.E. Keyes, R.J. Forster, L. Dennany, Insights into electrochemiluminescent enhancement through electrode surface modification, The Analyst, 138 (2013) 677-682.

[17] E.J. O'Reilly, L. Dennany, D. Griffith, F. Moser, T.E. Keyes, R.J. Forster, Ground and excited state communication within a ruthenium containing benzimidazole metallopolymer, Phys Chem Chem Phys, 13 (2011) 7095-7101.

[18] L. Dennany, E.J. O'Reilly, P.C. Innis, G.G. Wallace, R.J. Forster, The influence of poly (2methoxyaniline-5-sulfonic acid) on the electrochemical and photochemical properties of a highly luminescent ruthenium complex, Electrochim Acta, 53 (2008) 4599-4605.

[19] K.M. Molapo, A. Venkatanarayanan, C.M. Dolan, U. Prendergast, P.G. Baker, E.I. Iwuoha, T.E. Keyes, R.J. Forster, High efficiency electrochemiluminescence from polyaniline:ruthenium metal complex films, Electrochem Commun, 48 (2014) 95-98.

[20] C.G. Cameron, P.G. Pickup, Metal-Metal Interactions in a Novel Hybrid Metallopolymer, J Am Chem Soc, 121 (1999) 11773-11779.

[21] L. Dennany, T.E. Keyes, R.J. Forster, Surface confinement and its effects on the luminescence quenching of a ruthenium-containing metallopolymer, The Analyst, 133 (2008) 753-759.

[22] L. Dennany, C.F. Hogan, T.E. Keyes, R.J. Forster, Effect of Surface Immobilization on the Electrochemiluminescence of Ruthenium-Containing Metallopolymers, Anal Chem, 78 (2006) 14121417.

[23] L. Dennany, P.C. Innis, G.G. Wallace, R.J. Forster, Reversible Photoinduced Electron Transfer in a Ruthenium Poly(2-methoxyaniline-5-sulfonic acid) Composite Film, J Phys Chem B, 112 (2008) 1290712912.

[24] A.J. Bard, C.P. Keszthelyi, H. Tachikawa, N.E. Tokel, On The Efficiency of Electrogenerated Chemiluminescence, in: M.J. Cormier, D.M. Hercules, J. Lee (Eds.) Chemiluminescence and Bioluminescence, Springer US, Boston, MA, 1973, pp. 193-208.

[25] W.L. Wallace, A.J. Bard, Electrogenerated chemiluminescence. 35. Temperature dependence of the ECL efficiency of tris (2,2'-bipyridine)rubidium (2+) in acetonitrile and evidence for very high excited state yields from electron transfer reactions, The Journal of Physical Chemistry, 83 (1979) 1350-1357. [26] J. Van Houten, R.J. Watts, Temperature dependence of the photophysical and photochemical properties of the tris(2,2'-bipyridyl)ruthenium(II) ion in aqueous solution, J Am Chem Soc, 98 (1976) 4853-4858.

[27] L.M. Moretto, T. Kohls, D. Badocco, P. Pastore, N. Sojic, P. Ugo, Electrochemiluminescence of $\mathrm{Ru}($ bpy) $32+$ loaded in Nafion Langmuir-Blodgett films: Role of the interfacial ultrathin film, J

Electroanal Chem, 640 (2010) 35-41. 
Table 1; Homogeneous charge transfer diffusion coefficients $\left(D_{C T}\right)$ and quenching rate data.

\begin{tabular}{|l|l|l|l|}
\hline Polymer & $\boldsymbol{D}_{C T}\left(\mathbf{c m}^{2} \mathbf{s}^{-1}\right)$ & $\phi_{E C L}$ & $\begin{array}{l}\text { Quenching } \\
\text { Sphere radii }(\mathbf{n m})\end{array}$ \\
\hline$\left[\mathrm{Ru}(\mathrm{bpy})_{2}(\mathrm{PVP})_{10}\right]^{2+}$ & $9.2 \pm 1.1 \times 10^{-11}$ & 0.178 & 12 \\
\hline $\mathrm{Nafion}-\left[\mathrm{Ru}(\mathrm{bpy})_{3}\right]^{2+}$ & $2.3 \pm 0.8 \times 10^{-11}$ & 0.146 & 11 \\
\hline$\left[\mathrm{Ru}(\mathrm{bpy})_{2}(\mathrm{PPyBBIM})_{10}\right]^{2+}$ & $8.2 \pm 1.2 \times 10^{-10}$ & 0.033 & 15 \\
\hline $\begin{array}{l}{\left[\mathrm{Ru}(\mathrm{bpy})_{3}\right]^{2+} \text { Solution }} \\
\text { Phase }\end{array}$ & $8.6 \pm 1.1 \times 10^{-5}$ & 5.0 & $\mathrm{~N} / \mathrm{A}^{*}$ \\
\hline
\end{tabular}

All values based on averaged results from 5 independent measurements.

*Applies to static quenching governed by Perrin Model, solution phase quenching adheres to Stern-Volmer quenching dynamics.

Figure 1: (a) Potential dependence of the ECL intensity for Nafion- $\left[R u(b p y)_{3}\right]^{2+}$ modified electrode (blue line), $\left[R u(b p y)_{2}(P V P)_{10}\right]^{2+}$ (red line) and $\left[R u(b p y)_{2}(P P y B B I M)_{10}\right]^{2+}$ (black line) films on GC electrodes obtained in the presence of $0.5 \mathrm{mM} \mathrm{Na}_{2} \mathrm{C}_{2} \mathrm{O}_{4}$ in $0.1 \mathrm{M} \mathrm{PBS}$ at $\mathrm{pH} 6$ as the co-reactant. The potential was scanned from $0.2 \mathrm{~V}$ to a maximum of $1.4 \mathrm{~V}$ vs $\mathrm{Ag} / \mathrm{AgCl}$ at a scan rate of $100 \mathrm{mVs}^{-1}$. Inset shows $E C L$ dependence as a function of $\left[\mathrm{Na}_{2} \mathrm{C}_{2} \mathrm{O}_{4}\right]$. (b) Structures of $\left[\mathrm{Ru}(\text { bpy })_{2}(\mathrm{PPyBB} I M)_{10}\right]^{2+}$ (top) and $\left[R u(b p y){ }_{2}(P V P)_{10}\right]^{2+}$ (bottom) metallopolymers.

Figure 2: Typical solid state luminescence spectra for composite films of (a) $\left[R u(b p y)_{2}(P P y B B I M)_{10}\right]^{2+}(b)$ Nafion- $\left[R u(b p y)_{3}\right]^{2+}$ and (c) $\left[\left[R u(b p y)_{2}(P V P)_{10}\right]^{2+}\left(\Gamma=(2.1 \pm 0.2) \times 10^{-8} \mathrm{~mol} \mathrm{~cm}^{-2}\right)\right.$, in $0.1 \mathrm{M} \mathrm{LiClO}_{4}$ with increasing amounts of $R u^{3+}$ present obtained by holding the voltage from $0.1-1.0 \mathrm{~V} v \mathrm{vs} . \mathrm{Ag} / \mathrm{AgCl}$. As the voltage increases from $0.1 \mathrm{~V}$ to $1.0 \mathrm{~V}$ a decrease in emission at $612 \mathrm{~nm}$ is observed as a result of $R u^{2+*}$ quenching by increasing $R u^{3+}$ concentrations. (d) Dependence of the normalised emission intensity on the $R u^{3+}$ quencher concentration for composite films of $\left[R u(b p y)_{2}(P P y B B I M)_{10}\right]^{2+}$ (black squares), $\left[R u(b p y)_{2}(P V P)_{10}\right]^{2+}$ (red triangles) and $\left[R u(b p y)_{3}\right]^{2+}$ in Nafion (blue circles) according to the Perrin model of static quenching. Plots based on the steady state emission intensity data in Figure 2 (a), (b) and (c). 